\title{
A before and after study of the impact of academic detailing on the use of diagnostic imaging for shoulder complaints in general
} practice

\author{
Norm A Broadhurst ${ }^{1}$, Christopher A Barton*2, Debra Rowett ${ }^{3}$, Lisa Yelland ${ }^{2}$, \\ David K Martin ${ }^{1}$, Angela Gialamas ${ }^{2}$ and Justin J Beilby ${ }^{2}$
}

\begin{abstract}
Address: ${ }^{1}$ Department of Orthopaedics, Finders University, Bedford Park, South Australia, Australia, ${ }^{2}$ Discipline of General Practice, School of Population Health and Clinical Practice, University of Adelaide. Adelaide, South Australia. Australia and ${ }^{3}$ DATIS, Repatriation Hospital, Daw Park, South Australia. Australia

Email: Norm A Broadhurst - norm.broadhurst@flinders.edu.au; Christopher A Barton* - christoher.barton@adelaide.edu.au; Debra Rowett - Debra.Rowett@rgh.sa.gov.au; Lisa Yelland - lisa.yelland@adelaide.edu.au; David K Martin - dkmartin@bigpond.net.au; Angela Gialamas - angela.gialamas@adelaide.edu.au; Justin J Beilby - justin.beilby@adelaide.edu.au

* Corresponding author
\end{abstract}

This article is available from: http://www.biomedcentral.com/I47/-2296/8/12

(C) 2007 Broadhurst et al; licensee BioMed Central Ltd.

This is an Open Access article distributed under the terms of the Creative Commons Attribution License (http://creativecommons.org/licenses/by/2.0), which permits unrestricted use, distribution, and reproduction in any medium, provided the original work is properly cited.

\begin{abstract}
Background: The aim of this study was to assess the impact that Academic Detailing (AD) had on General Practitioners' use of diagnostic imaging for shoulder complaints in general practice and their knowledge and confidence to manage shoulder pain.

Methods: One-to-one Academic Detailing (AD) for management of shoulder pain was delivered to 87 General Practitioners (GPs) in metropolitan Adelaide, South Australia, together with locally developed clinical guidelines and a video/DVD on how to examine the shoulder. Three months after the initial $A D$ a further small group or an individual follow up session was offered. A 10 -item questionnaire to assess knowledge about the shoulders was administered before, immediately after, and 3 months after $A D$, together with questions to assess confidence to manage shoulder complaints. The number of requests for plain film (X-ray) and ultrasound (US) imaging of the shoulder was obtained for the intervention group as well as a random comparison group of $90 \mathrm{GP}$ 's from the same two Divisions. The change in the rate of requests was assessed using a log Poisson GEE with adjustment for clustering at the practice level. A linear mixed effects model was used to analyse changes in knowledge.
\end{abstract}

Results: In an average week 54\% of GPs reported seeing fewer than 6 patients with shoulder problems. Mean (SD) GP knowledge score before, immediately after and 3-months after AD, was 6.2/10 (I.5); 8.6/10 (0.96) and; 7.2/10 (I.5) respectively $(p<0.000 \mathrm{I})$. Three months after $A D, G P s$ reported feeling able to take a more meaningful history, more confident managing shoulder pain, and felt their management of shoulder pain had improved. Requests for ultrasound imaging were approximately $43.8 \%$ higher in the period 2 years before detailing compared to six months after detailing $(p<0.000 \mathrm{I})$, but an upward trend toward baseline was observed in the period 6 months to I year after AD. There was no statistically significant change in the rate of requests from before to after $A D$ for plain-radiographs $(P=0.1 \mathrm{I})$. No significant changes in the rate of requests over time were observed in the control groups.

Conclusion: These results provide evidence that AD together with education materials and guidelines can improve GPs' knowledge and confidence to manage shoulder problems and reduce the use of imaging, at least in the short term. 


\section{Background}

Shoulder pain is third following back and neck pain as a musculoskeletal reason for presenting to general practice in Australia. Approximately $10 \%$ of the adult population are expected to visit a General Practitioner (GP) for shoulder pain at least once in a lifetime $[1,2]$.

Despite the finding that $50 \%$ of acute shoulder pain resolves in 8-10 weeks many patients present with the anticipation of having some kind of imaging [3,4]. There are a range of diagnostic imaging tests that can be used in the evaluation of shoulder pain including plain radiographs, arthrography, computed tomography, ultrasound, and magnetic resonance imaging [5]. The history and physical examination are keys to most shoulder pain diagnoses, particularly when used in combination. Often no imaging is required, or plain radiographs are the sole imaging study needed [5].

Over recent years the Diagnostic Imaging Section of the Australian Government Department of Health and Ageing identified a marked increase in the use of ultrasound imaging for problems relating to the shoulder. The increase in the number of ultrasounds performed for shoulder complaints have been at considerable cost to the Commonwealth Health Insurance Commission (HIC). In the year to April 2002, the cost increased by $110 \%$ to $\$ 12.9$ million. The number of $\mathrm{x}$-ray and ultrasound services performed in 2001-02 when compared with the previous year also increased by $110 \%$ to 152,073 investigations. GPs in Australia are unable to order magnetic resonance imaging (MRI) and so these costs are not considered here.

A project devised in three parts was initiated by the Musculoskeletal Ultrasound Project Team of the Australian Government Department of Health and Ageing and operated through the auspices of the Musculoskeletal Foundation of Australia. Stage I was to determine what was written by GPs on imaging request forms and then to compare this with the radiologist's report. This study found that about one third (34\%) of requests for ultrasound imaging of the shoulder contained no tangible information to assist the radiological examination [6]. When a clinical diagnosis was provided by a GP, the degree of accuracy with the ultrasound findings was only $22 \%$.

The results from Stage II [7] showed most imaging is ordered at the first visit of the patient presenting with shoulder pain, with the majority of patients having imaging ordered within five weeks of the first GP visit. Age (4565 years), pain on activity, and shoulder pain present for $\geq 5$ weeks increased the likelihood for a person to have imaging. Imaging (results similar in both Stage I and Stage II) revealed some pathology in $75 \%$ of patients.

The preliminary work completed in Stage I and Stage II provided good evidence that guidelines for imaging of shoulder complaints need to be established, and that GPs might benefit from education about management of shoulder problems. Stage III of the study presented here, sought to improve the assessment and management of shoulder complaints through the use of Academic Detailing to GPs, and to improve the knowledge and confidence of GPs to manage shoulder pain.

\section{Methods}

Ethics approval was granted from the University of Adelaide Human Research Ethics Committee on 19 November 2003.

A 'before and after' study design was implemented involving two metropolitan divisions of General Practice (The Adelaide Central and Eastern (ACE) Division and the Western Division of General Practice (WDGP) who assisted the study team to recruit General Practitioners from the membership lists of these Divisions. GPs were eligible to participate if they were members in one of these Divisions and were working $\geq 0.5$ full time equivalent (FTE). All GPs in the two Divisions who met the selection criteria were invited to participate.

GPs interested in participating in the study faxed a signed agreement to the Drug and Therapeutic Information Service (DATIS) at the Repatriation General Hospital, South Australia who made appointments with the GPs for Academic Detailing.

\section{Details of academic detailing}

Two Specialists provided the Academic Detailing to GPs (NB and DM), at the GPs practice between December 2004 and March 2005.

Arrangements for Academic Detailing were coordinated through the DATIS Director (DR) and her staff, who are recognised experts in the field of Academic Detailing. The Detailers (NB and DM) provided one to one guidance to GPs on how to correctly assess the shoulder, and after having corrected the technique the GP was provided with education materials that included a DVD and guidelines (see Additional file 1). These were left with the GPs to be used during future patient assessments. The Detailing session lasted from 45 to 60 minutes.

At the initial AD visit each GP received:

- The reason for and the objectives of the study 
- An evidence-based outline for shoulder imaging

- A video/DVD on the anatomy and examination of the shoulder. The Detailer used the video as a guide during an active demonstration on how to examine the shoulder.

- A reference information sheet to aid the management of patients with shoulder pain (see Additional file 1).

Three months after the initial AD a follow up session was offered either in small groups or on a one-to-one basis.

\section{Questionnaires}

Demographic information about the GP and the practice they work in was collected by questionnaire. GPs then completed a ten-item questionnaire to determine knowledge about identifying and managing shoulder problems (see Additional file 2). The knowledge questionnaire was repeated immediately after the detailing, and again at the follow up visit when GPs also completed a 27-item questionnaire regarding confidence to manage shoulder problems and satisfaction with the AD model.

Questions asked referred to:

- The project generally;

- Assessment of study materials

- Assessment of the AD presentation

- Use of treatment modalities as a consequence of the Detailing.

Table I: Demographic details of participating General Practitioners'.

\begin{tabular}{|c|c|c|c|}
\hline & & $\mathrm{ACE}^{2}$ & WDGP $^{3}$ \\
\hline & & $N(\%)$ & $N(\%)$ \\
\hline \multirow[t]{2}{*}{ Gender } & Male & $34(60.7 \%)$ & 19 (6I.3\%) \\
\hline & Female & $22(39.3 \%)$ & $12(38.7 \%)$ \\
\hline \multirow[t]{5}{*}{ GP Age } & $<35$ & $2(3.6 \%)$ & $2(6.5 \%)$ \\
\hline & $35-44$ & 17 (30.4\%) & $5(16.1 \%)$ \\
\hline & $45-54$ & 25 (44.6\%) & II (35.5\%) \\
\hline & $55-64$ & $10(17.9 \%)$ & $10(32.3 \%)$ \\
\hline & $65+$ & $2(3.6 \%)$ & 0 \\
\hline \multirow[t]{4}{*}{ Years in general practice } & $<=5$ years & $3(5.4 \%)$ & I (3.2\%) \\
\hline & $6-15$ years & $15(26.8 \%$ & $4(12.9 \%)$ \\
\hline & $16-25$ years & $28(50 \%)$ & $17(54.8 \%)$ \\
\hline & $26+$ years & $10(17.9 \%)$ & $7(22.6 \%)$ \\
\hline \multirow[t]{6}{*}{ Number of full time equivalents at practice } & Solo & 7 (I2.5\%) & $8(25.8 \%)$ \\
\hline & $2 \mathrm{GPs}$ & 7 (12.5\%) & $8(25.8 \%)$ \\
\hline & $3 \mathrm{GPs}$ & $9(16.1 \%)$ & $3(9.7 \%)$ \\
\hline & 4 GPs & $5(8.9 \%)$ & $4(12.9 \%)$ \\
\hline & 5 or more GPs & 27 (48.2\%) & $4(12.9 \%)$ \\
\hline & Other & I (I.8\%) & I (3.2\%) \\
\hline Completion of Family Medicine & Yes & $27(48.2 \%$ & $8(25.8 \%)$ \\
\hline \multirow[t]{3}{*}{ Program or RACGP training program } & No & $29(51.8 \%)$ & $19(61.3 \%)$ \\
\hline & Current & 0 & $2(6.5 \%)$ \\
\hline & Registrar & & \\
\hline \multirow[t]{2}{*}{ Vocationally Registered } & Yes & $55(98.2 \%)$ & $29(93.5 \%)$ \\
\hline & No & I (I.8\%) & 0 \\
\hline \multirow[t]{4}{*}{ Number of patients with shoulder pain in an 'average' week } & $<6$ & $31(55.4 \%)$ & $16(51.6 \%)$ \\
\hline & $6-15$ & $22(39.9 \%)$ & II (35.5\%) \\
\hline & $16-25$ & $3(5.4 \%)$ & I (3.2\%) \\
\hline & $26+$ & 0 & I (3.2\%) \\
\hline \multirow[t]{6}{*}{ Approximate number of patients seen in a normal week } & $0-25$ & $6(10.7 \%$ & I (3.2\%) \\
\hline & $26-50$ & 12 (21.4\%) & $4(12.9 \%)$ \\
\hline & $51-75$ & $15(26.8 \%)$ & $3(9.7 \%)$ \\
\hline & $76-100$ & $11(19.6 \%)$ & $8(25.8 \%)$ \\
\hline & $101-125$ & $9(16.1 \%)$ & $9(29 \%)$ \\
\hline & $126-150$ & $3(5.4 \%)$ & $4(12.9 \%)$ \\
\hline
\end{tabular}

IPercentages do not always total 100 due to missing data

${ }^{2} \mathrm{ACE}=$ Adelaide Central and Eastern Division of General Practice

${ }^{3}$ WDGP $=$ Western Division of General Practice 


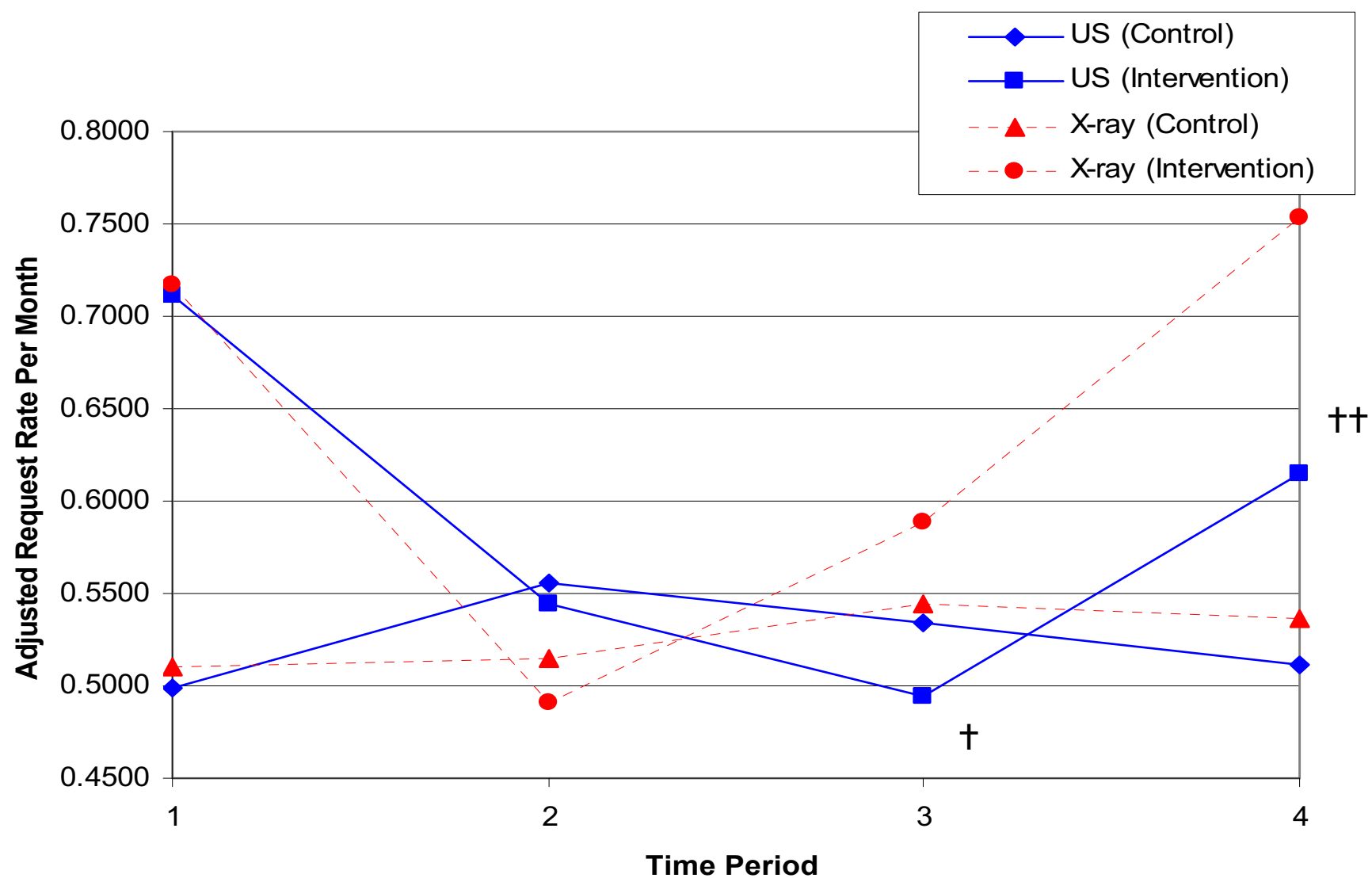

\section{Figure I}

Adjusted rates of requests by time for plain shoulder x-ray (MBS Item 57703) and ultrasound (MBS Item 55808). Time Period I represents the two-year period before academic detailing; 2) represents the month of academic detailing; 3 ) represents the six-month period after academic detailing; 4) represents the six-month period after time 3 . $\dagger-$ Time Period 3 compared with Time Period I in the Academic Detailing group ( $<<0.01$ ). $\dagger \dagger-$ Time Period 4 compared to Time Period 3 in the Academic Detailing group $(p=0.036)$.

\section{Imaging request data}

The number of requests for plain film (Medicare Benefits Schedule Item number 57703) and US imaging (Medicare Benefits Schedule item number \#55808) of the shoulder was provided by the HIC for all GPs on a month-bymonth basis for the period January 2001 to March 2005.

Imaging requests were also obtained for a comparison group of 90 randomly selected GPs from the Adelaide Central and Eastern Division of General Practice (60 GPs), and the Western Division of General Practice (30 GPs) membership list.

\section{Statistical analysis}

Data was initially entered into a Microsoft Access database and then transferred to SPSS version 12.0 for data cleaning purposes and preliminary data analysis. Frequency and range checks were carried out to ensure quality of data entry. Further statistical analysis was undertaken using SAS version 9.1 (Cary, NC, USA).

Demographic data and data collected from the confidence to manage shoulder problems questionnaire were analysed descriptively using frequencies. GP knowledge scores were analysed using a linear mixed effects model to investigate whether there was a change in knowledge across the three different testing times. Practice was included as a random effect and the model allowed for heterogeneity of variances across the testing times.

A log Poisson GEE was fitted to the HIC data of monthly imaging requests to investigate whether there was a change in the rate of requests made over four time periods of interest (period 1 = two year period before academic detailing, period 2 = month of Detailing, period $3=$ six month period after Detailing, and period $4=$ six month 
Table 2: Post Hoc testing of adjusted imaging rates for ultrasound (MBS item 55808).

\begin{tabular}{|c|c|c|c|c|c|c|}
\hline Comparison & 'Estimate & 95\% Lower Limit & 95\% Upper Limit & ChiSq & P-value & Sig \\
\hline Period I: control vs. academic detailing & 0.701 & 0.470 & 1.045 & 3.04 & 0.081 & NS \\
\hline Period 2: control vs. academic detailing & 1.022 & 0.597 & $\mathrm{I} .749$ & 0.01 & 0.938 & NS \\
\hline Period 3: control vs. academic detailing & 1.080 & 0.690 & 1.689 & 0.11 & 0.737 & NS \\
\hline Period 4: control vs. academic detailing & 0.831 & 0.565 & 1.223 & 0.88 & 0.348 & NS \\
\hline Control: period I vs. period 2 & 0.896 & 0.629 & 1.277 & 0.37 & 0.545 & NS \\
\hline Control: period I vs. period 3 & 0.933 & 0.758 & 1.150 & 0.42 & 0.517 & NS \\
\hline Control: period I vs. period 4 & 0.975 & 0.791 & 1.202 & 0.06 & 0.813 & NS \\
\hline Control: period 2 vs. period 3 & $1.04 \mid$ & 0.714 & 1.519 & 0.04 & 0.834 & NS \\
\hline Control: period 2 vs. period 4 & 1.088 & 0.768 & 1.540 & 0.22 & 0.636 & NS \\
\hline Control: period 3 vs. period 4 & 1.045 & 0.846 & 1.289 & 0.17 & 0.685 & NS \\
\hline Academic detailing: period I vs. period 2 & 1.306 & 0.951 & $\mathrm{I} .795$ & 2.72 & 0.099 & NS \\
\hline Academic detailing: period I vs. period 3 & 1.438 & 1.254 & 1.649 & 26.94 & $<.0001$ & $*$ \\
\hline Academic detailing: period I vs. period 4 & 1.156 & 0.956 & 1.398 & 2.24 & 0.134 & NS \\
\hline Academic detailing: period 2 vs. period 3 & 1.101 & 0.807 & $1.50 \mid$ & 0.37 & 0.544 & NS \\
\hline Academic detailing: period 2 vs. period 4 & 0.885 & 0.643 & 1.218 & 0.56 & 0.453 & NS \\
\hline Academic detailing: period 3 vs. period 4 & 0.804 & 0.656 & 0.986 & 4.39 & 0.036 & $*$ \\
\hline
\end{tabular}

Nb. No adjustment has been made for multiple comparisons

IThe estimate represents the post hoc comparison Rate Ratio NS - Not Significant

$*$ Indicates $\mathrm{p}<0.05$.

period after time period 3) and whether this change was different in the $\mathrm{AD}$ and control groups. Adjustment for clustering was made at the practice level. In order to define the four time periods of interest for a control GP, an 'Academic Detailing' month had to be assigned. This assignment was made randomly and ensured that within each division, an approximately equal percentage of GPs in the control and $\mathrm{AD}$ groups were assigned to each month in which $\mathrm{AD}$ was carried out. Results were adjusted for month since the data exhibited seasonal variation.

A p-value $\leq 0.05$ was required for statistical significance.

\section{Results}

Of the 369 ACE Division GPs 59 (16\%) agreed to participate and out of 247 GPs in the WDGP 33 (13\%) participated. Five GPs who initially responded to the invitation to participate either withdrew consent or were unable to complete the study leaving a total of 87 for the final analysis. Approximately half of GPs reported seeing fewer than 6 patients with shoulder problems a week. Further demographic details of the GPs can be found in Table 1.

Figure 1 shows the time-adjusted rate of requests for plain $\mathrm{x}$-ray and ultrasound made by GPs in the two years before the study (Time period 1), during the month of AD (Time period 2), in the six months immediately after AD (Time period 3), and in the next six-month period (Time period 4). There was no evidence to suggest a change in the rate of requests over the different time periods for plain x-ray in the intervention group compared to the control group $(P=0.11)$. Figure 1 also shows the time-adjusted rate of requests for ultrasound made by intervention and control group GPs. There is strong evidence to suggest that changes in the rate of requests over time periods were different for the $\mathrm{AD}$ and control groups $(\mathrm{p}=0.02)$. The rate ratio describes the ratio of the rate of an event in one group to the rate in another group. In this context, we can use the rate ratio to compare the rate of requests between the $\mathrm{AD}$ and control groups, or during different time periods within the same group. Post hoc testing indicates that the estimated rate ratio comparing time 1 to time 3 for the $\mathrm{AD}$ group is $1.438(\mathrm{p}<0.0001)$. This means that requests were approximately $43.8 \%$ more frequent during time 1 compared to time 3 in the academic detailing group, after adjusting for everything else in the model.

However, the estimated rate ratio comparing time 3 to time 4 is $0.80413(\mathrm{p}=0.036)$. This means that requests were approximately $19.6 \%$ less frequent during time 3 compared to time 4 in the academic detailing group, after adjusting for everything else in the model. This indicates that in the period 6 months to 1 year after the academic detailing, the number of requests for ultrasound trended significantly upward toward baseline, but still tended to be less frequent than prior to the academic detailing, although this did not reach statistical significance (time 1 vs time $4, \mathrm{p}=0.13$ ) (Table 2).

There were no other statistically significant differences in the rate of requests, either comparing time periods within treatment groups or comparing $\mathrm{AD}$ and control at each time period (Table 2).

The mean (St Dev) GP knowledge before detailing was $6.2 / 10(1.5)$. Immediately after the detailing, this rose to 
Table 3: GPs confidence to manage musculoskeletal problems three months after participating in academic detailing

\begin{tabular}{|c|c|c|}
\hline Item & & $\mathrm{N}(\%)^{*}$ \\
\hline \multirow[t]{5}{*}{ I found the visit helpful for increasing management skills } & Strongly Agree & $22(26.5 \%)$ \\
\hline & Agree & $56(67.5 \%)$ \\
\hline & No Change & $4(4.8 \%)$ \\
\hline & Disagree & $\mathrm{I}(1.2 \%)$ \\
\hline & Strongly Disagree & $0(0 \%)$ \\
\hline \multirow[t]{5}{*}{ I have been able to take a more meaningful history } & Strongly Agree & $7(8.4 \%)$ \\
\hline & Agree & $62(74.7 \%)$ \\
\hline & No Change & $14(16.9 \%)$ \\
\hline & Disagree & $0(0 \%)$ \\
\hline & Strongly Disagree & $0(0 \%)$ \\
\hline \multirow[t]{5}{*}{ My examination process is better developed } & Strongly Agree & $9(10.8 \%)$ \\
\hline & Agree & $65(78.3 \%)$ \\
\hline & No Change & $9(10.8 \%)$ \\
\hline & Disagree & $0(0 \%)$ \\
\hline & Strongly Disagree & $0(0 \%)$ \\
\hline \multirow[t]{5}{*}{ I am managing shoulder pain more confidently } & Strongly Agree & $6(7.4 \%)$ \\
\hline & Agree & $60(74.1 \%)$ \\
\hline & No Change & $15(18.5 \%)$ \\
\hline & Disagree & $0(0 \%)$ \\
\hline & Strongly Disagree & $0(0 \%)$ \\
\hline \multirow[t]{5}{*}{ From the history and examination I can identify the area/structure of the pain more readily } & Strongly Agree & $6(7.4 \%)$ \\
\hline & Agree & $57(68.7 \%)$ \\
\hline & No Change & $20(24.1 \%)$ \\
\hline & Disagree & $0(0 \%)$ \\
\hline & Strongly Disagree & $0(0 \%)$ \\
\hline \multirow[t]{5}{*}{ My management of shoulder pain has improved since the Detailing } & Strongly Agree & $10(12 \%)$ \\
\hline & Agree & $62(74.7 \%)$ \\
\hline & No Change & II (13.3\%) \\
\hline & Disagree & $0(0 \%)$ \\
\hline & Strongly Disagree & $0(0 \%)$ \\
\hline
\end{tabular}

$* \%$ does not always total 100 due to missing data.

$8.6 / 10$ (0.96). Three months after the detailing, knowledge remained higher compared to pre-test knowledge (7.2/10 (1.5). There was very strong evidence of a change in knowledge amongst the 87 GPs over the three testing times $(\mathrm{p}<0.0001)$ and post hoc analyses revealed significant differences in mean scores between each pair of testing times $(\mathrm{p}<0.0001$ in each case). Knowledge was greatest immediately after academic detailing, and remained significantly higher than baseline 3 months after academic detailing.

There was no evidence to suggest that any of the demographic variables had an effect on the average test score, except for the total number of patients per week ( $\mathrm{p}=$ 0.0496). However, the post hoc analysis did not reveal a clear relationship between the total number of patients per week and average knowledge score and this result is considered an artefact.

Three months after academic detailing most GPs reported feeling able to take a more meaningful history, felt more confident managing shoulder pain, and felt that their management of shoulder pain had improved (Table 3 ).

\section{Discussion}

The major goal of this study was to reduce the number of referrals for shoulder imaging, and this was achieved in the first six months after academic detailing for ultrasound imaging of the shoulder, but not for $x$-ray imaging. However, over the next six month period this could not be sustained and the frequency of requests for ultrasound imaging returned toward pre-academic detailing levels. While these GPs had increased knowledge and were more confident in managing shoulder pain, this was in contrast to the trend toward baseline in the number of imaging requests seen 12 months after detailing.

An assessment as to why GP's gravitated to their pre-AD level of practice in respect to managing shoulder pain is needed. Failure to maintain the reduced use of ultrasound could be due to limited exposure to patients with shoulder pain; time restraints in general practice that might lead to regression after the initial encouragement; or the threat of patient dissatisfaction or even legal challenge, therefore unnecessary imaging is ordered in the absence of a confident assessment. The later point may reflect declining confidence in assessment with time, as indicated by the 
decay in knowledge, and increasing use of ultrasound six months to one year after the initial academic detailing.

While previous studies on musculoskeletal management have shown deficiencies in the management of patients with pain in general practice, this study has established potential cost savings in the short term, from reduced use of ultrasound imaging. A more detailed and concentrated educational program might be necessary to sustain changes observed in imaging use for management of shoulder problems.

Guidelines for managing some musculoskeletal problems are well known and have a proven cost benefit [8-12]. The cost savings per item number from this study based on a $40 \%$ decrease in 6 months translates to a saving of $\sim \$ 7000$ per doctor per year. The big question would be whether a detailed educational program on shoulder management would be cost effective and enduring?

\section{Limitations of the study}

The primary limitation of this study is the low participation rate (16\% in ACE Division and 13\% in the WDGP). Those GPs that did participate were self-selected and so it is possible that they had a special interest in musculoskeletal problems. An inspection of the number of imaging requests made per month indicate that GPs who volunteered for academic detailing requested more imaging than control group GPs who did not volunteer to participate in academic detailing. However, there was a large range in the number of patients that GPs reported as presenting with shoulder complaints in an average week. Hence, it is likely that some of the GPs in this study had a special interest in musculoskeletal problems, but clearly not all did. A second limitation is that we did not evaluate whether our intervention actually made the use of imaging more appropriate according to the guideline. A final limitation relates to repeated testing of knowledge. Since the same questions were asked at each testing time, there may have been a learning effect.

\section{Conclusion}

Academic Detailing has proven to be a means of containing shoulder imaging use in the short term. Further research is required to determine if the increase in knowledge and confidence for managing shoulder problems translates into better clinical management as well as reducing cost in the long term, while not compromising health outcomes and quality of life.

\section{Competing interests}

The author(s) declare that they have no competing interests.

\section{Authors' contributions}

NB was involved in conception and design, gaining funding, he developed study materials including guidelines and Academic Detailing materials, performed Academic Detailing, oversaw day-to day management of the project, provided insight to data analysis, and helped draft the manuscript. CB provided day-to-day management of project, sought ethics approvals, recruited GP participants, entered and analysed data, provided insight to data analysis, and helped draft the manuscript. DR was involved in conception and design, provided advice on the Academic Detailing program, co-ordinated delivery of Detailing, and provided insight to data analysis. LY performed advanced statistical analyses and interpretation and helped draft the manuscript. DM helped develop Academic Detailing materials and performed Academic Detailing. AG was involved in conception and design, gaining ethics approval and recruiting GPs prior to going on maternity leave. JB was involved in conception and design, gaining funding and provided insight to data analysis. All authors read and approved the final manuscript.

\section{Additional material}

\section{Additional File 1}

A guideline for shoulder imaging developed in consensus by 6 orthopaedic surgeons. Guidelines developed for the study for use by GPs to manage shoulder pain.

Click here for file

[http://www.biomedcentral.com/content/supplementary/14712296-8-12-S1.doc]

\section{Additional File 2}

Assessment of knowledge about musculoskeletal problems of the shoulder. The questionnaire used in the study to assess GP knowledge about management of shoulder pain.

Click here for file

[http://www.biomedcentral.com/content/supplementary/14712296-8-12-S2.doc]

\section{Acknowledgements}

Funded by the Diagnostic Imaging Reform Implementation Package, Diagnostic Imaging Section, the Australian Department of Health and Ageing.

We would like to thank Donna Logan from the Drug and Therapeutics Information Service for her assistance with organisation of the Academic Detailing sessions. Don Allan and Janette Bridger from the Adelaide Central and Eastern Division of General Practice assisted with recruiting and liaising with GPs in this Division. We also thank Catherine Trott and Arie Bansemer, from the Western Division of General Practice for assistance liaising with GPs in the Western Division of General Practice.

\section{References}

I. Mitchell C, Adebajo A, Hay E, Carr A: Shoulder pain: diagnosis and management in general practice. BMJ 2005, 33 I: | | 24- | | 28. 
2. van der Heijden GJ, van der Windt DA, Kleijnen J, Koes BW, Bouter LM: Steroid injections for shoulder disorders: a systematic review of randomised controlled trials. Br J Gen Pract 1996, 46:309-316.

3. van der Heijden GJ: Shoulder disorders: a state of the art review. Bailliere's Clinical Rheumatology 1999, 13:287-309.

4. van der Windt DA, Koes BW, Boeke AJ, Deville W, De Jong BA, Bouter LM: Shoulder disorders in general practice: the prognostic indicators of outcome. $\mathrm{Br} J$ Gen Pract 1996, 46(4I 0):519-523.

5. Stevenson JH, Trojian T: Evaluation of shoulder pain. The Journal of Family Practice 2002, 5 I (7):605-6I I.

6. Broadhurst $N$, Baghurst $T$, MacLaren $S$ : Ultrasound imaging for shoulder pain in general practice. Aust Fam Physician 2004, 33(8):668-669.

7. Broadhurst NA, Gialamas A, McElroy HJ, Beilby JJ: How do Australian GP's manage shoulder dysfunction? Aust Fam Physician 2004, 33 (I0):86I-2, 864.

8. Hoffman JR, Wolfson AB, Todd K, Mower WR: Selective cervical spine radiography in blunt trauma: methodology of the national Emergency X-radiography Utilizatio Study (NEXUS). Ann Emerg Med 1998, 32(4):461-469.

9. Spitzer WO, Skovron ML, Salmi LR, Cassidy JD, Duranceau J, Suissa S, Zeiss E: Scientific monograph of the Quebec Task Force on Whiplash-Associated Disorders: redefining "whiplash" and its management. Spine 1995, 20(8 SuppI): IS-73S.

10. Stiell IG, Greenberg GH, McKnight RD, Nair RC, McDowell I, Worthington JR: A study to develop clinical decision rules for the use of radiography in acute ankle injuries. Ann Emerg Med 1992, 2 I (4):384-390.

11. Stiell IG, Greenberg GH, Wells GA, McKnight RD, Cwinn AA, Cacciotti T, McDowell I, Smith NA: Derivation of a decision rule for the use of radiography in acute knee injuries. Ann Emerg Med 1995, 26(4):405-413.

12. Stiell IG, Wells GA, Vandemheen KL, Clement CM, Lesiuk H, De Maio VJ, Laupacis A, Schull M, McKnight RD, Verbeek R, Brison R, Cass D, Dreyer J, Eisenhauer MA, Greenberg GH, MacPhail I, Morrison L, Reardon M, Worthington J: The Canadian C-Spine Rule for radiography in alert and stable trauma patients. JAMA 200।, 286(I5): |84|-|848.

\section{Pre-publication history}

The pre-publication history for this paper can be accessed here:

http://www.biomedcentral.com/1471-2296/8/12/prepub

Publish with Biomed Central and every scientist can read your work free of charge

"BioMed Central will be the most significant development for disseminating the results of biomedical research in our lifetime. "

Sir Paul Nurse, Cancer Research UK

Your research papers will be:

- available free of charge to the entire biomedical community

- peer reviewed and published immediately upon acceptance

- cited in PubMed and archived on PubMed Central

- yours - you keep the copyright

Submit your manuscript here:

http://www.biomedcentral.com/info/publishing_adv.asp
BioMedcentral 